\title{
SURVEY OF HYBRID EDFA/RAMAN IN C AND L BANDS
}

\section{Estudio del amplificador híbrido EDFA-RAMAN en las bandas C Y L}

JUAN DAVID BONILLA*

\author{
Recibido: 25 de diciembre de 2016. Aceptado: 30 de diciembre de 2016
}

DOI: $h$ ttp://dx.doi.org/10.21017/rimci.2017.v4.n7.a18

\section{Resumen}

Los amplificadores ópticos han tenido un gran avance en los últimos años. Inicialmente, se realizó la amplificación de señales ópticas pasando la señal óptica al dominio eléctrico, luego, la señal amplificada regreso al dominio óptico. Después, para evitar la distorsión de la señal, surgen amplificadores ópticos. El primer amplificador de este tipo fue el amplificador SOA, que generó mucho ruido en la señal. El amplificador EDFA, se basa en la fibra dopada, aparece para mejorar el proceso de amplificación con alta ganancia. Posteriormente, los amplificadores Raman, que se basan en la excitación de fenómenos no lineales en fibra proporcionando mayor ganancia de amplificación que EDFA y añade la menor cantidad de ruido ASE a la amplificación de la señal óptica. Los amplificadores híbridos son el futuro de los sistemas DWDM, debido a su alta ganancia de ancho de banda y bajo nivel de ruido, permitiendo aumentar la eficiencia del sistema. Este artículo discute los diferentes amplificadores híbridos, específicamente los amplificadores HOA RAMAN-EDFA, analizando la configuración de RAMAN-EDFA-RAMAN, sus ventajas y desventajas en los actuales sistemas DWDM.
\end{abstract}

Palabras clave: DWDM, EDFA, FRA, Amplificador óptico híbrido, longitud de onda de bombeo.

\begin{abstract}
Optical amplifiers have had a breakthrough in recent years. Initially, amplification of optical signals was performed passing the optical signal to the electrical domain, then the amplified signal back again to the optical domain. Subsequently, to avoid signal distortion, optical amplifiers arise. The first amplifier of this type was the amplifier SOA, which generated a lot of noise in the signal. The EDFA amplifier, which is based on doped fiber, appears to improve the noise figure with higher gain in the amplification process. Later, Raman amplifiers, which are based on the excitation of nonlinear phenomena in fiber provide greater amplification gain than EDFA and adds the least amount of ASE noise to the amplified optical signal. Hybrid amplifiers are the future of DWDM systems because its high bandwidth gain and low noise figure, allowing to increase system efficiency. This article discusses the different hybrid amplifiers, specifically the HOA RAMANEDFA amplifiers, by analyzing the RAMAN-EDFA-RAMAN configuration, its advantages and disadvantages in current DWDM systems are studied.
\end{abstract}

Keywords: DWDM, EDFA, FRA, hybrid optical amplifier, pumping wavelength.

\section{INTRODUCCIÓN}

$\mathrm{F}_{\text {IbER AMPLIFIERS such as fiber Raman amplifier }}$ (FRA) and Erbium doped fiber amplifier (EDFA) have a key role in optical transmission systems. These amplifiers have emerged as a promising solution in extending transmission capacity of dense wavelength division multiplexed (DWDM) optical networks.
Raman amplifiers have attracted huge attention, due that any wavelength within the transparency window of an optical fiber, can be amplified by simply adjusting the pump wavelength [1]. However, since the Raman-gain spectrum is not flat inherently, multiple pumping techniques or a broadened pump with gain equalizers are normally used for gain flattening and many optical devices are required for wideband optical amplification [2].

* Ingeniero de telecomunicaciones de la Universidad de Antioquia, con énfasis en comunicaciones ópticas, específicamente en el diseño de redes de transporte DWDM long-haul y redes de acceso FTTH. Correo electrónico: jdavid.bonilla@udea.edu.co 
The wide-band-EDFA covers two or three bands since it separately amplifies optical signals of each band. Generally, EDFAs are used as line amplifiers which are composed of two or three gain stages. At these stages are incorporated some components such as, dispersion compensating fibers $(D C F)$, gain flattening filters, optical attenuators, and tap couplers [3]. DCF is well known solution in compensating the fiber dispersion. However, high loss of DCF degrades noise figure of EDFA.

On the other hand, the invention of EDFA twenty years ago, temporally supplanted ongoing research on hybrid optical amplifiers (HOA), but due to huge growth of the current data traffic has produced enormous demand for transmission bandwidth of DWDM optical communication systems [4], and based on that demand arose the need of reinvestigate the implementation of hybrid amplifiers on DWDM networks, but this time combining the advantages of both EDFA and Raman amplifiers, becoming the hybrid amplifier in an advantageous element and an economically attractive solution to compensate the optical fiber losses and losses introduced by the intermediate nodes [5].

The hybrid Raman-EDFA is designed in order to minimize the impairments due to fiber nonlinearities and to enhance the gain bandwidth and/ or gain flatness of DWDM system because it can provide broad gain bands in any required wavelength region by properly setting the pump wavelengths, which is inaccessible for EDFA amplifiers [6].

This paper is outlined as follows. In Section II, a state of the art of operational principle of optical amplifiers is presented. Section III presents an overview of hybrid optical amplifiers, while Sections IV and V present some used configurations of hybrid optical amplifiers and a simulation and analysis of one of this configurations. Finally, Section VI are conclusions.

\section{STATE-OF-THE-ART}

Optical amplifiers are a great advance on longhaul networks, allowing a direct amplification over the optical signal without the use of transceivers, improving the gain, reducing noise and increasing distance between amplifiers, which reduces costs over the network.

The two most used optical amplifiers systems are based on semiconductor lasers which uses stimulated emission and the other system is based on doping the fiber with rare earth elements, in this case erbium ions (EDFA), or using the gain provided by scattering Raman (nonlinear effects).

First optical amplifiers are knowing as Semiconductor Laser Amplifiers (SLAs), they have similar behavior to semiconductor laser, the difference between them is that SLAs have no feedback that creates the oscillation. In these amplifiers, the active zone is built using alloy elements such as indium, gallium, phosphorus and arsenic [7].

There are several types of SLAs, but the most used are the resonant cavity (Fabry-Perot amplifier FPA), the Travelling Wave Amplifier (TWA) and those without cavity called quasi travelers or Near Travelling Wave Amplifier (NTWA).

One characteristic of FPAs are the cavity mirrors which are $30 \%$ reflective, producing resonance inside the cavity.

The main operational condition of FPAs is the current injection which is under the threshold current $\left(l_{\text {th }}\right)$, for a laser working at this condition do not exist laser emission, but there is population inversion, and therefore stimulated emission exists, due to the photons input from the fiber to the structure. Furthermore, due to the own light emission of the FPA the amplified light has some noise. On the other hand, an inconvenience of FPA is its frequency response, since have a pass-band filter (FP) with a similar behavior to a FPA, consisting of a series of regularly spaced passbands behavior.

Because of all above reasons, these type of amplifiers are rarely used in optical networks.

Currently, TWA amplifiers are the most widely used due to their benefits in saturation, bandwidth and noise. Their structure consists on a directly polarized p-n junction, where the cavity mirrors 
have a thin silicon dioxide or nitride layer causing a reflectivity less than $\left(10^{-3}\right)$.

Removing mirrors cavity avoids resonance, which causes a flat amplification, although a small gain is produced. On the other hand, due to the strong reduction of cavity resonance, threshold current considerably increases impeding the existence of own laser emissions.

Amplifiers without resonant cavity (TWA and NTWA), have an amplification between 15-35 dB, low power consumption, and are suitable for single mode fibers.

Other class of SLA are those based on injection latching which consists on semiconductor lasers polarized above the threshold $\left(l_{\text {th }}\right)$, this generates resonance in the cavity producing a huge amplification with a high noise thanks to laser emission in cavity. These amplifiers are rarely used in optical networks due to their low efficiency [7].

SLA amplifiers have some disadvantages, such as the match of SLAs with optical fiber is inefficient because of SLAs have a rectangular symmetry and a few wavelengths can be amplified at the same time. Therefore, to avoid this problem optical amplifiers based on fiber such as EDFA and Raman amplifiers emerge.

EDFA amplifier consists on a fiber whose core is doped with erbium ions. Such impurities produce spreading on transition bands, which combined with a pumping laser generate population inversion.

When the optical signal passes through the fiber, this is amplified due that erbium ions fall to their fundamental level energy, resulting a gain in signal. It should be remembered that spontaneous emission generates ASE noise which is added to the amplified optical signal. The suitable wavelengths to pumping an EDFA are 1480nm (using an InGaAsP diode laser) and 980nm (using an InGaAs diode laser). Using a wavelength of $1480 \mathrm{~nm}$ a lot of noise is generated and this affects the optical signal, although this wavelength is immune to saturation gain. On the other hand, pumping on 980nm causes a completely opposite behavior.
Currently, EDFA amplifier is widely used in optical networks because it works on «C band" (around 1550nm). The EDFA's gain is around between 30-50 dB, depending of the input power. A lower input power produces higher gain and vice versa (Fig. 1). Maximum gain of EDFAs is on 1530-1535 nm.

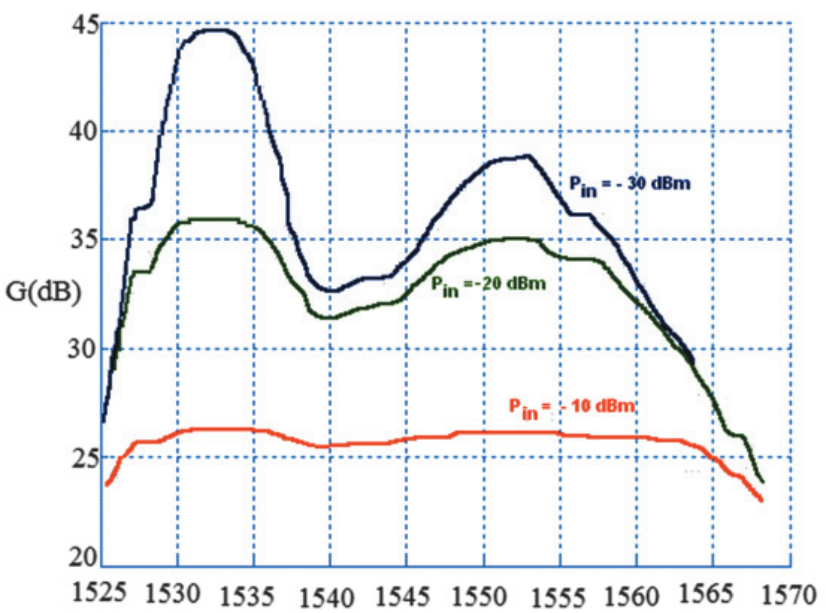

Fig. 1. EDFA gain for several input power values. [7]

There are three configurations for the EDFA amplifier pumping which can see in Fig. 2.

Nowadays EDFA configuration 1(a) is the most used, in this configuration the optical signal to be amplified and the pump signal are together injected to the EDFA by using a coupler, the first isolator is used to avoid the spread outward of the generated spontaneous emission (ASE noise). Pumping and amplification are made on the same direction of signal propagation (forward pumping). After doped fiber other isolator is placed, avoiding amplification of any reflected signal. Finally, an optical filter is used to filter the ASE noise generated by the amplifier.

Second configuration $1(b)$ is different from the first one because it has a pumping in the opposite direction to the signal propagation (reverse pumping). The input isolator is used to avoid the pumping signal propagation outside the amplifier. The advantage of this configuration is that it allows higher gains, but its noise characteristics are worse. 
Third configuration 1 (c) is a combination of the two previous configurations. It has a double pumping known as bidirectional pumping which allows that gain can be double. This scheme is widely employed for amplifiers implementation.

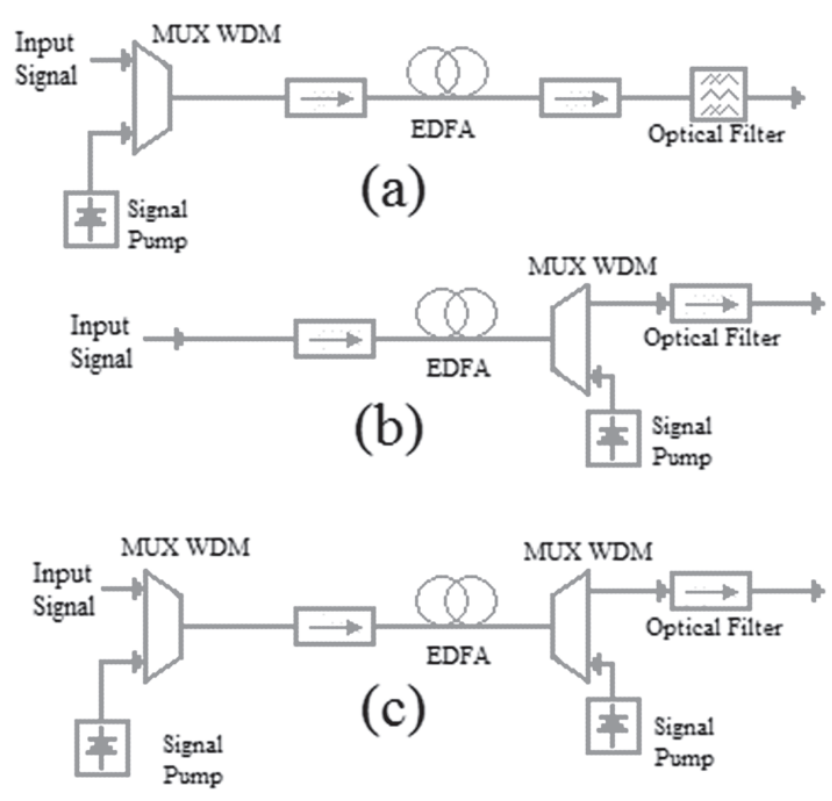

Fig. 2. EDFA configurations. [7]

In table 1 summarizes the typical parameters of an EDFA amplifier.

Table 1. Typical parameters of EDFA. [7] [8]

\begin{tabular}{lcc}
\hline Pumping wavelength & $\mathbf{1 4 8 0} \mathbf{~ n m}$ & $\mathbf{9 8 0} \mathbf{~ m}$ \\
\hline Pumping efficiency $(\mathrm{dB} / \mathrm{mW})$ & 5 & 10 \\
Noise figure $(\mathrm{dB})$ & 5.5 & $3-4.5$ \\
Saturation output power $(\mathrm{dBm})$ & 20 & 5 \\
Gain $(\mathrm{dB})$ & 40 & 50 \\
Pumper power $(\mathrm{mW})$ & $50-200$ & $10-20$ \\
\hline
\end{tabular}

EDFA amplifier do not presents a uniform gain for a variation on the wavelength, this is due to increasing input power reducing gain until it becomes constant (saturation point).

Following are some features of EDFA that make it the most used amplifier.

1. Low generated noise.

2. Gain saturation does not cause distortion.
3. Low insertion losses due to cylindrical geometry of EDFAs.

4. Gain is less sensitive to the signal due to cylindrical geometry of EDFAs.

Main drawback of an EDFA amplifier is that it only operates in the third telecommunications window. Non-uniform gain for every wavelength is another drawback of EDFAs, but this can be solved by operating near to the saturation point because at this point gain is flatter [7] [8].

There are other types of amplifiers that allows operation on other telecommunications windows such as Praseodymiun Doped-Fiber Amplifier (PDFA) which is the same amplifiers as the EDFA but the main difference between them is the use of Praseodymium to dope the core of the optical fiber, allowing this device amplify in the second window. The main disadvantage of PDFAs is that gain is lower than for an EDFA.

Raman and Brillouin effects are nonlinear phenomena which consist on pumping to a fiber with high power, with this, photons begin to give a little of their energy to the lattice vibration (phonons). If the given energy is low, around $0,2 \mathrm{meV}(50 \mathrm{GHz}$ of frequency) the stimulated effect is Brillouin, but if the given energy is higher, around $10 \mathrm{meV}$ Raman effect is generated [8].

Raman amplifier fundamentally consist of an optical fiber which is pumped with a high power (1W) to stimulate Raman effect (SRS stimulated Raman scattering) and thus amplify the optical signal. The maximum gain is $40 \mathrm{~dB}$ (using $1 \mathrm{~W}$ of pumping). These amplifiers are very used on DWDM systems. FRAs are typically used on configuration of reverse pumping, where the wavelengths of pumping are introduced to optical fiber on opposite direction to DWDM signals. Thus it is ensured that most part of the amplification occurs at the end of the fiber path where the signal levels are lower, preventing turn the power level at the start of each stage of amplification beyond the threshold of nonlinear effects. FRAs can operate both in $\mathrm{C}$ band and $\mathrm{L}$ band, but due to their low gain on C-band, these amplifiers are commonly used in L band. To amplify signals on C-band (1530-1565nm), the pumping signal should be placed in a range of $1426-1461 \mathrm{~nm}$. To amplify 
signals in L-band (1565-1625), the pumping wavelength is around 1480nm. In general, each wavelength pumping provides gain at a frequency below of $13.2 \mathrm{THz}$ (pumping signal should be placed on a wavelength approximate to $104 \mathrm{~nm}$ ).

When FRAs are used in presence of channels on both C-band and L-band, the wavelength pumping on $\mathrm{C}$ band losses a lot of power to amplify the wavelengths pumping on $L$ band, i.e., at same time the $C$ band channels provide some amplification to the $\mathrm{L}$ band channels, causing less power to shorter wavelengths and higher power to longer wavelengths. Therefore, the wavelengths pumping on $C$ band require more power than wavelengths on $\mathrm{L}$ band [8].

Following are some advantages of Raman amplifiers:

1. Covers a range of wavelengths uncovered by EDFA (L band).

2. ASE noise is lower than EDFAs.

3. By improving the optical signal-to-noise ratio (OSNR) of entire system it can be obtained lower effective noise figure than $3 \mathrm{~dB}$ or even negative values that are unobtainable separately with EDFAs.

\section{HYBRID OPTICAL AMPLIFIERS}

Nowadays, high capacity networks have been possible due to implementation of DWDM optical transport systems, which have enhanced performance of optical networks through the use hybrid optical amplifiers. As mentioned above at this paper, exists several types of optical amplifiers such as SOA, PDFA, EDFA, Raman, among others. Because of this there are different configurations of hybrid amplifiers which will be seen below.

\section{A. Hybrid SOA-EDFA}

SOA-EDFA can be used to extend the gain spectrum of an EDFA. But it generates higher amount of ASE noise than in the hybrid configurations such as EDFA-DRA (Distributed Raman Amplifier) or SOA-DRA. This types of hybrid amplifiers are not applied in long haul DWDM systems [9] because ASE noise affects the total performance of the system, resulting in a low received signal level, i.e., a high bit error rate (BER) [10].

\section{B. Hybrid SOA-EDFA}

In DRA-SOA hybrid amplifiers, Raman amplifier increases overall system gain and reduces SOA gain tilt i.e., the use of DRA eliminates nonlinear effects produced by SOAs. However, the use of multiple SOAs in optical links is not common, because SOAs produce a high distortion in the optical signal. This broad gain bandwidth $(>80$ $\mathrm{nm}$ ) amplifiers can be designed to operate in any wavelength region compatible with single-mode optical fiber [10] [11].

\section{Hybrid EDFA-EYCDFA}

One disadvantage of EDFA is the different gain for several wavelengths, this due to doping concentration, and EYCDFA (Erbium Ytterbium Co-Doped Fiber Amplifier) suppresses concentration quenching effect which generates higher flatness gain under certain pump power. Hybrid EDFA and EYCDFA provides a flat gain of $36 \mathrm{~dB}$ with noise figure in a range of 4 to $4.2 \mathrm{~dB}$ for a fiber length of $14 \mathrm{~m}$ and a wavelength pumping at $980 \mathrm{~nm}[10]$.

\section{Hybrid EYCDFA-SOA}

EYDWA-SOA hybrid amplifiers are very common on metropolitan networks, due to provides a high and flat gain because of the high doping of EYDWA, also, provides a large output power and gain with less variation due to the presence of SOA amplifier [10].

\section{E. Hybrid EDFA-TDFA}

EDFA provides enough flattening gain but gain spectrum is narrow, therefore the number of DWDM channels amplified is reduced. Thus there is a necessity to improve the amplification bandwidth of EDFA, and TDFA (Thulium Doped Fiber Amplifier) is a viable alternative to improve the limitations of EDFA [10] [14] [15].

\section{F. Hybrid TDFA-FRA}

FRA-TDFA hybrid amplifiers work in short wavelength band (S-band) region, because 
combining the gain spectrum of TDFA and FRA. In this case, FRA and TDFA use a similar type of pump laser. Theoretical gain varies from 20 to 24 $\mathrm{dB}$ within a wavelength region from 1460 to 1525 nm [10] [17] [19].

\section{G. Hybrid Raman-EDFA}

The goal of this paper is to analyze this type of amplifiers, because EDFA and Raman works optimally in different bands ( $\mathrm{C}$ band and $\mathrm{L}$ band respectively). Since the beginning of the century has been studied how to combine the use of these amplifiers to achieve a flat gain in the $\mathrm{C}$ and $\mathrm{L}$ bands, i.e., a constant gain uniform for the different spectral components of those bands. Blue graph in Fig. 3 shows above affirmation. This wide flatness gain bandwidth is because of the gain spectrum of FRA can vary by adjusting the pump powers and pump wavelengths, which is used to increase the amplification bandwidth of EDFA.

The noise figure of Raman amplifiers is much lower than that of EDFAs, so to achieve a higher gain with lower noise figure or a wider amplification band, is needed to use an EDFA in combination with a FRA.

Some important advantages of HOA RamanEDFA are the generation of high gain and good power conversion efficiency by EDFAs, and more flexible gain bandwidth design, low noise, high capacity to mitigate fiber nonlinearities produced by Raman and the enhancement of the gain bandwidth and/or gain flatness of DWDM system. This allows that all channels have a similar amplification, with a low noise, increasing the length between amplifiers such that reduces cost of the optical network.

Some important drawbacks of Raman-EDFA amplifiers are the requirements of several pumping wavelengths to generate a high flatter gain. On the other hand, by increasing the number of pumping lasers, the ripple significantly decreases, although, the global gain of system increase $5 \mathrm{~dB}$ for each laser. It is recalled that the use of many pumping lasers is not efficient, but this can be mitigated somewhat by increasing the number of channels using a Raman-EDFA configuration [18] [19].

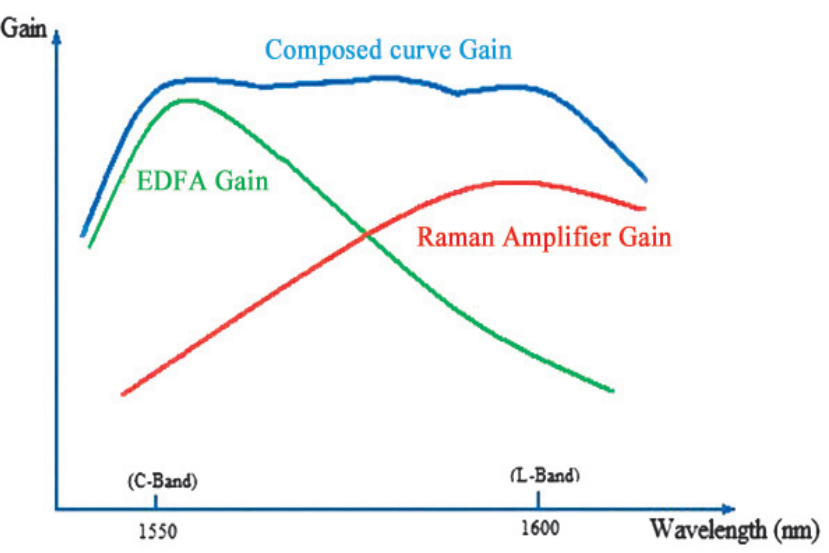

Fig. 3. Gain Raman-EDFA. [7]

\section{HoA EDFA-RAMAN CONFIGURATIONS}

Several types of configurations for the implementation of EDFA-Raman amplifiers have been proposed with the passing of years, following are some of them.

\section{A. Configurations with pump recycling}

Configuration in Fig. 4(a) proposes to optimize Raman+EDFA hybrid amplifiers for broadband applications. This optimization technique to design flat gain hybrid amplifiers also proposes pump recycling. In this case, the first stage of the configuration is a WDM optical communication system, which passes through a dispersion compensating fiber (DCF) which have a dispersion coefficient of $-98 \mathrm{ps} / \mathrm{nm}-\mathrm{km}$ and is based on a Raman amplifier $(12.6 \mathrm{~km})$. The second stage is an EDFA amplifier using a $10 \mathrm{~m}$ of erbium-doped fiber (EDF). Optimization is performed for amplifiers with two pump lasers (pumping (a)) and three pump lasers (pumping (b)) as can be seen on table 2 .

The pumped DCF as a Raman amplifier has two main advantages, the first one the amplification band can be extended within the transparency window of the optical fiber by simply changing the pumping wavelengths, and the second one, both losses and dispersion compensation in the transmission fiber can be obtained at the same time[18].

Configurations on Fig. 4 were used on another investigation, in which several pumping lasers 
Table 2. Pump wavelength and pump power [18].

\begin{tabular}{lccccc}
\hline \multicolumn{3}{c}{ Pumping(a) } & \multicolumn{4}{c}{ Pumping(b) } \\
\hline Wavelength (nm) & 1425 & 1468 & 1414.5 & 1426.5 & 1472 \\
PumpPower(mw) & 296.3 & 61.3 & 244.1 & 269.9 & 60.1 \\
\hline
\end{tabular}

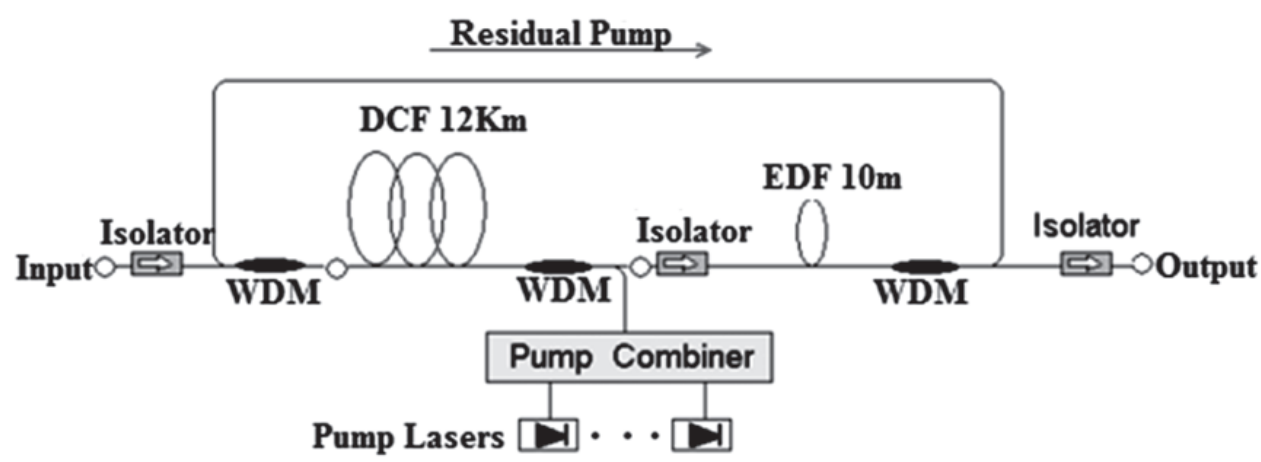

(a)

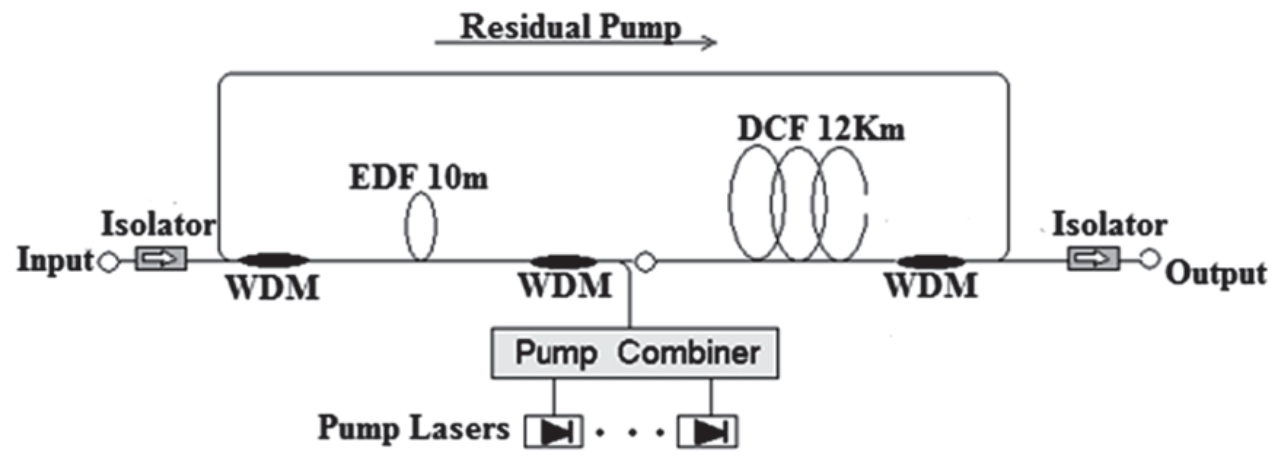

(b)

Fig. 4. Schematic design of HOA Raman-EDFA [18] [19]

(Table 3) were used, and the number of channels $(8,16,32,64$, and 128) was varied from so it was determined that the configuration EDFA-Raman $(4 \mathrm{~b})$ is providing better services in terms of global gain system $40 \mathrm{~dB}$ and a low noise figure with 8 channels. Also it was determined that the ripple tends to decrease as the pumping lasers number increases.

Whereas the average global gain increases approximately $5 \mathrm{~dB}$ per each pumping laser included. The increase of input channels number can provide better results than the increase of pumping lasers when is used an EDFA-Raman hybrid amplifier [19].
Table 3. Pump wavelenghts for configurations of Fig. 3 [19].

\begin{tabular}{lccc}
\hline $\begin{array}{l}\text { Number of } \\
\text { pump lasers }\end{array}$ & $\begin{array}{c}\text { Wavelength } \\
\text { (nm) }\end{array}$ & $\begin{array}{c}\text { Power of } \\
\text { each pump } \\
\text { lasers (mW) }\end{array}$ & $\begin{array}{c}\text { Pumping } \\
\text { global power } \\
\text { (mW) }\end{array}$ \\
\hline 1 & 1425.0 & 231.3 & 231.3 \\
\hline 2 & 1425.4 & 291.0 & 368.9 \\
\hline 3 & 1451.0 & 77.9 & \\
\hline 4 & 1423.0 & 288.9 & 529.7 \\
& 1425.4 & 176.5 & \\
& 1465.8 & 64.3 & \\
& 1421.7 & 91.4 & \\
& 1422.9 & 211.9 & \\
& 1424.0 & 204.1 & \\
\hline
\end{tabular}




\section{B. Configurations for DWDM systems}

Configuration at Fig. 5(a) uses a single EDFA working in $\mathrm{C}$ band or L band, while Fig. 5 (b) has two parallel EDFAs which can be used for any of the wavelengths of $C$ and $L$ bands [20]. A further proposal configuration contains a hybrid amplifier located $100 \mathrm{~km}$ from the transmitter (Fig. 6.), i.e., this is a line amplifier. Raman amplifier is pumped with two wavelengths looking for a flattened signal. It is important to remember that the power spectrum of the optical signal in a Raman amplifier is affected by Raman pumping (only counter propagation is considered at this case), Raman amplifier spontaneous emission, ASE noise and Rayleigh back scattering. Moreover, the pump power does not remain constant along the Raman fiber. Some important details are set forth in Table 4 [21]. Other configurations for DWDM systems can be seen in Fig. 7, where the Raman stage is always operated in the counter-pumped geometry, due to smaller pumping noise coupling onto the signal. In
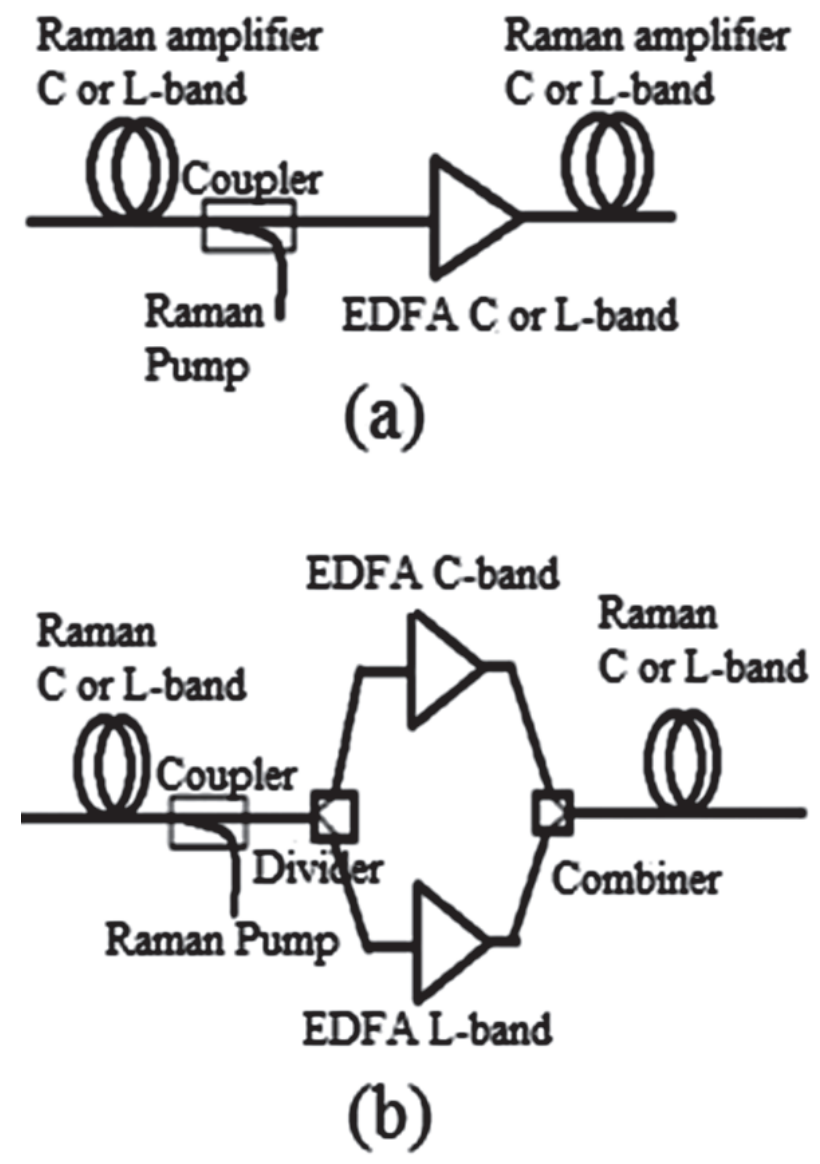

Fig. 5. Configurations HOA Raman-EDFA [20].

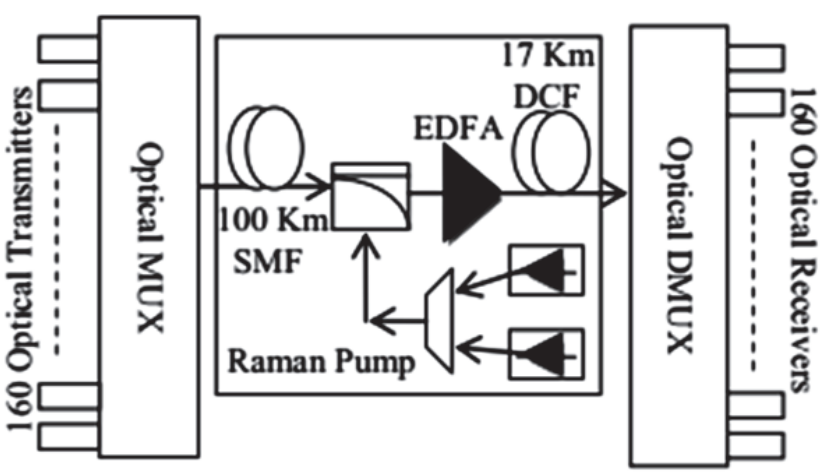

Fig. 6. Proposed HOA for DWDM systems [21].

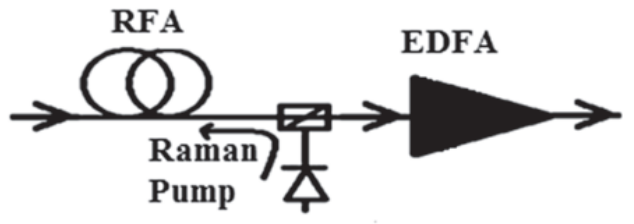

(a)

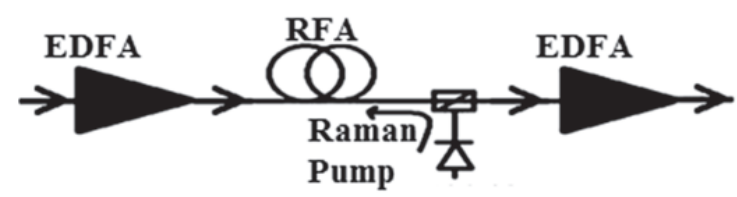

(b)

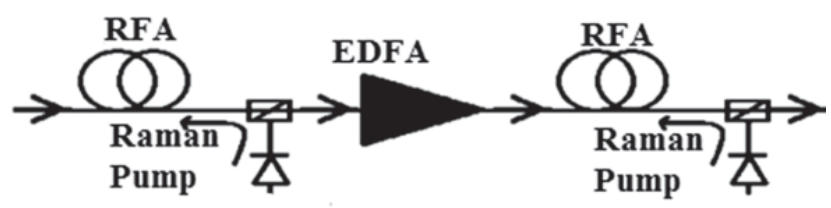

(c)

Fig. 7. Proposed HOA for DWDM systems [22].

Table 4. Pump frequency and pump power of fig. 6 [21]

\begin{tabular}{lcccc}
\hline Fiber & $\begin{array}{c}\text { Loss } \\
(\mathbf{d B} / \mathbf{K m})\end{array}$ & $\begin{array}{c}\text { Dispersión } \\
(\mathbf{p s} / \mathbf{n m k m}) \\
(\mathbf{T H z})\end{array}$ & $\begin{array}{c}\text { Pump } \\
\text { frequency }\end{array}$ & $\begin{array}{c}\text { Pump } \\
\text { power } \\
(\mathbf{m W})\end{array}$ \\
\hline SMF & 0.2 & 16 & 207 & 650 \\
\hline DCF & 0.5 & -90 & 201 & 250 \\
\hline
\end{tabular}

Rev. Ingeniería, Matemáticas y Ciencias de la Información Vol. 4 / Núm. 7 / enero-junio de 2017; pág. 13-24 
this configuration were used the data presented on tables 5, for Raman and EDFA amplifiers respectively. In the hybrid configuration of Fig. 7(a), the optical signal enters the Raman stage before undergoing further amplification in the cascaded EDFA. First amplification stage in hybrid amplification of Fig. 7(b) is composed of an EDFA which is followed by a hybrid Raman stage and finally and EDFA amplifier. In this case, the first EDFA is a power Booster.

In hybrid amplifier of Fig. 7(c) three times amplification occurs by the Raman amplifier followed by a hybrid EDFA-Raman.

Table 5. EDFA-Raman parameters for DWDM [22]

\begin{tabular}{ll}
\hline Parameters & Value \\
\hline Raman fiber length & $12 \mathrm{~km}$ \\
Raman loss & $0.2 \mathrm{~dB} / \mathrm{km}$ \\
Raman Pump wavelength & $1,453 \mathrm{~nm}$ \\
Raman Pump power & $500 \mathrm{~mW}$ \\
Raman Pump attenuation & $0.2 \mathrm{~dB} / \mathrm{km}$ \\
Dispersion at reference frequency & $2.15 \mathrm{ps} / \mathrm{nm} \mathrm{km}$ \\
Reference frequency for dispersion & $1,550 \mathrm{~nm}$ \\
Operating temperature & $300 \mathrm{~K}$ \\
EDFA PARAMETERS & \\
Out power & $32 \mathrm{~mW}$ \\
Gain shape & Flat \\
Maximum small signal gain & 35.6 \\
Noise figure & $4.5 \mathrm{~dB}$
\end{tabular}

Simulations were carried out using 100-laser sources operating at $1,546.725-1,551.575 \mathrm{~nm}$, 1,543.45-1,553.15nm, 1,536.9-1,556.3nm, 1,523.81,562.6nm, and 1,497-1,575.2nm for $6.25,12.5,25$, 50 , and $100 \mathrm{GHz}$, respectively. Each laser source has a light beam of $1 \mathrm{~mW}$ of power. These laser beams are modulated by a sine square amplitude modulator with an excess loss of $4 \mathrm{~dB}$. The simulated bit rate is at SONET/SDH rate (2.488Gbps) with a pseudorandom binary sequence. With respect to the overall power system performance, Raman-EDFA is found to have the best performance among the three types in the terms of quality factor, BER, and eye closure[22]. Shows the maximum single span distance of $220 \mathrm{~km}$ which is achieved by Raman-EDFA amplifier at acceptable BER $\left(4^{*} 10^{10}\right)$, quality factor $(15.8 \mathrm{~dB})$, and eye closure $(2.23 \mathrm{~dB})$ [22].

Simulation results have shown that the maximum acceptable bit rate for the $12.5 \mathrm{GHz}$ channel spacing DWDM system with the Raman-EDFA, RamanEDFA-Raman, and EDFA-Raman-EDFA, need not to be greater than 20,16, and 19Gbps, respectively [22].

Table 6 shows some proposed configurations of hybrid amplifiers where some important parameters such as gain flatness, gain bandwidth, gain, noise figure, number of channels are

Table 6. Configurations of hybrid optical amplifiers and results. [6] [10] [20]

\begin{tabular}{|c|c|c|c|c|}
\hline Hybrid Optical Amplifiers & $\begin{array}{l}\text { Gain and Noise } \\
\text { Figure (NF) }\end{array}$ & Gain Flatness & $\begin{array}{l}\text { Number of channels/ } \\
\text { channel spacing }\end{array}$ & $\begin{array}{c}\text { Gain } \\
\text { Bandwidth }[\mathrm{nm}]\end{array}$ \\
\hline EYDWA+SOA [6] & Gain $>14 \mathrm{~dB}$ & $\sim 0.75 \mathrm{~dB}$ & $\begin{array}{l}\text { Channels: } 100 \\
\text { Spacing: } 0.2 \mathrm{~nm}\end{array}$ & 20 \\
\hline EDFA+EYCDFA [13] & $\begin{array}{l}\text { Gain } \sim 36 \mathrm{~dB} \\
\text { NF: }-4 \text { to } 4.2 \mathrm{~dB}\end{array}$ & Flat & - & - \\
\hline EDFA+TDFA [15] & $\begin{array}{l}\text { Gain }>7 \mathrm{~dB} \\
\mathrm{NF}:<7 \mathrm{~dB}\end{array}$ & Gain variation radio $<0.4$ & - & 80 \\
\hline Raman +EDFA [16] & Gain $>12 \mathrm{~dB}$ & $\sim 1.2 \mathrm{~dB}$ & $\begin{array}{l}\text { Channels:35 } \\
\text { Spacing: } 1 \mathrm{~nm}\end{array}$ & 23.5 \\
\hline Raman+EDFA+DCF [21] & Gain $>10 \mathrm{~dB}$ & $<4.5 \mathrm{~dB}$ & $\begin{array}{l}\text { Channels: } 160 \\
\text { Spacing: } 0.2 \mathrm{~nm}\end{array}$ & 31.79 \\
\hline Raman+EDFA+FBG+DCF [23] & Gain $>4 \mathrm{~dB}$ & $<0.5 \mathrm{~dB}$ & Channels:26 & 80 \\
\hline Raman+EDFA [24] & Gain $>11 \mathrm{~dB}$ & $<3 \mathrm{~dB}$ & $\begin{array}{l}\text { Channels:16 } \\
\text { Spacing: } 0.8 \mathrm{~nm}\end{array}$ & 12.01 \\
\hline DRA+EDFA [6] & Gain $>24 \mathrm{~dB}$ & $\sim 1.15 \mathrm{~dB}$ & $\begin{array}{l}\text { Channels: } 100 \\
\text { Spacing: } 0.2 \mathrm{~nm}\end{array}$ & 20 \\
\hline
\end{tabular}


analyzed. The main proposal of these configurations is to reduce the noise figure and achieve the major gain flatness possible of HOA. As mentioned above, this paper focus on EDFARaman configurations. Analyzing Table 6, the highest value of flat gain was achieved for Raman+EDFA+DCF configuration where gain bandwidth is $31.79 \mathrm{~nm}$ while the noise figure was not study for this article.

\section{Results}

To analyze the behavior of a DWDM signal by using an EDFA+DRA amplifier configuration, a simulation is made by means of VPIphotonics software. DWDM signal is setting to transport 40 channels with a spacing channel of $100 \mathrm{GHz}(0.8 \mathrm{~nm})$.

Table 7 contains the EDFA and Raman amplifiers parameters used for the simulation. Raman amplifiers have a separation distance of $15 \mathrm{~km}$ and $18 \mathrm{~km}$ respectively. Forward and reverse pumping are used for Raman amplifiers, as can be seen at Fig. 8, where there is illustrated the used configuration for this simulation.

Raman amplifiers are working on L band, because of this, the pumping wavelength is chosen around of $1480 \mathrm{~nm}$. On the other hand, EDFA amplifier operates on $C$ band, by using a $1480 \mathrm{~nm}$ pumping wavelength, and a $100 \mathrm{~mW}$ power. This
Table 7. Simulation parameters.

\begin{tabular}{lcc}
\hline Amplifiers & $\begin{array}{c}\text { Pump wavelength } \\
\text { (nm) }\end{array}$ & $\begin{array}{c}\text { Pumper power } \\
\text { (mW) }\end{array}$ \\
\hline EDFA & 1480 & 100 \\
Raman & 1500 & 130 \\
$(15 \mathrm{~km})$ & 1489 & 135 \\
Raman & 1515 & 190 \\
$(18 \mathrm{~km})$ & 1520 & 200 \\
\hline
\end{tabular}

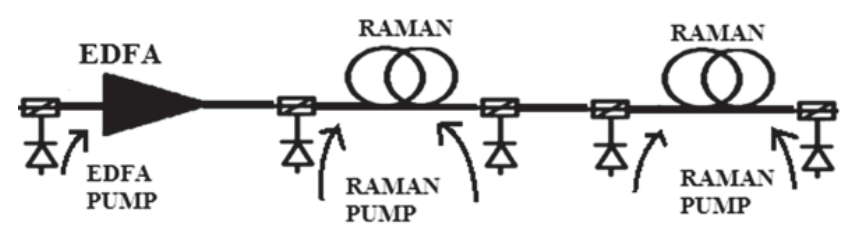

Fig. 8. HOA configuration for DWDM systems.

pumping power must be between 50 and $200 \mathrm{~mW}$ (see Table 1), this to avoid amplifier saturation. ASE noise is added to the optical signal, this due to the high value for EDFA pumping power, as can be seen on Fig. 9. The three used pumping wavelength are placed at right side of Fig. 9.

Amplification gain for band $\mathrm{L}$ channels is flat whilst channels on $C$ band have more variation on their gain, this because of DRA amplifiers achieve a flat gain on the entire L band, but due that EDFA amplifier don't provides a very flat gain, channels on $C$ band are affected (see Fig. 10).

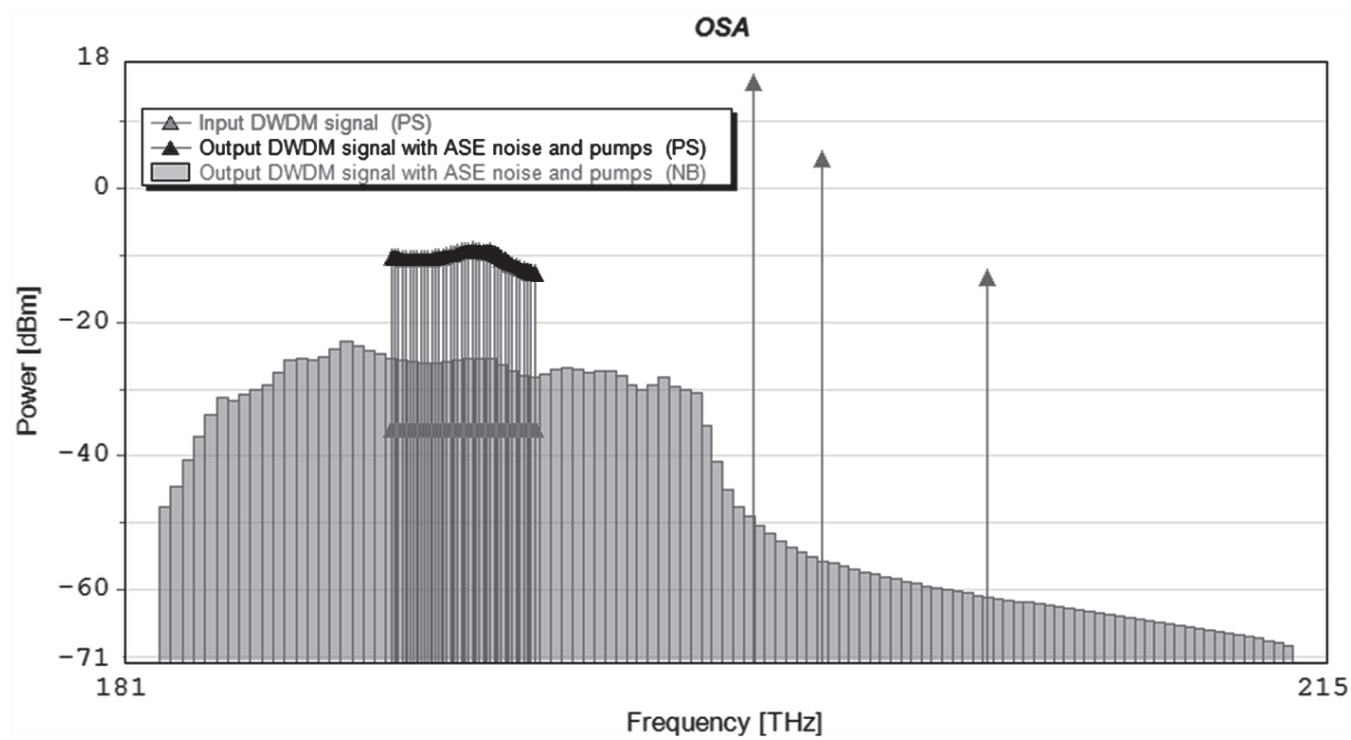

Fig. 9. Spectral analysis of HOA. 


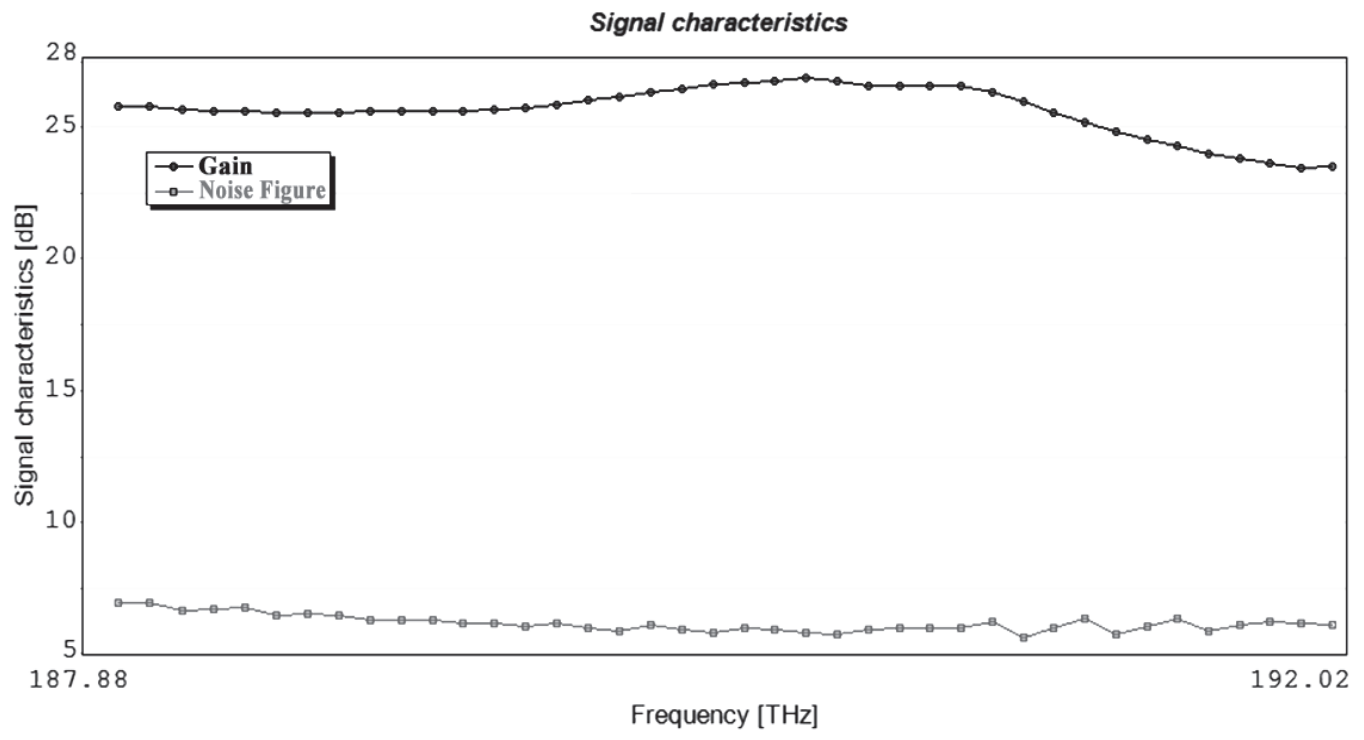

Fig. 10. Gain and Noise figure of HOA.

As mentioned above, ASE noise covers completely the optical signal (green line on Fig. 9).

Fig. 10 shows the HOA amplifier gain and noise figure. Variations on channel frequency causes changes on the noise figure, drastic variations occur for the EDFA operation band ( $\mathrm{C}$ band). At this operation band, amplifier gain is reduced, this could be overcome by increasing the pumping power for EDFA amplifier although this could produce some problems due to the amplification of ASE noise.

It is important to remember that the saturation gain for the EDFA amplifier is achieved for pumping powers over $200 \mathrm{~mW}$.

To reduce the quantity of ASE noise on amplified signal a more accurate optical filter is required, this to allow the improvement of the noise figure of HOA. Due that noise figure depends of the signal noise ratio at amplifier output, is required that less ASE noise be generated in amplification process for EDFA amplifier. On the other hand, EDFA gain could be duplicated if a dual pumping is deployed, i.e. forward and reverse pumping. Although it is not common to carry out this type of pumping.

\section{CONCLUSIONS}

The use of EDFA at the first HOA amplification stage adds a lot of ASE noise to the optical signal, and this causes the distortion of noise figure, which reduces drastically the amplifier performance and affects the signal flatness. To achieve a higher flat gain bandwidth, is necessary to find the adequate pumping wavelength. On the other hand, amplification gain depends of the pumping power which must be chosen on an adequate value to avoid the noise aggregation to the amplified signal.

Flat gain bandwidth obtained for the simulation is $2.7 \mathrm{THz}$, the achieved gain for this bandwidth is $27 \mathrm{~dB}$, with a variation of $\sim 1.3 \mathrm{~dB}$ and a minimum and maximum noise figure of $5.5 \mathrm{~dB}$ and $6.5 \mathrm{~dB}$ respectively. Comparing above simulation results with those on table 6 , it can be determined that proposed configuration have good results, although a better optical filter is required at EDFA output, to reduce the generated ASE noise.

Due to the wide flat gain bandwidth and low noise figure reached for hybrid amplifiers at the simulation, HOA can be a key element for DWDM long-haul transport networks.

\section{REFERENCES}

[1] M.N Islam. «Raman Amplifiers for Telecommunications»-1 Physical Principles, chapter 1. New York: Springer, 2004.

[2] H. Kidorf, K. Rottwitt, M. Nissov, M. Ma, and E. Rabarijaona, «Pump interactions in a $100-\mathrm{nm}$ 
bandwidth Raman amplifier,» IEEE Photon. Technol. Lett, vol. 11, no. 5, pp. 530-532, May 1999.

[3] K. Motoshima, et al., J. Lightwave Technol., 19, 17591767 (2001).

[4] H. Suzuki, M. Fujiwara, and K. Iwatsuki, «Application of super-DWDM technologies to terrestrial terabit transmission systems,» J. Lightw. Tech-nol., vol. 24, no. 5, pp. 1998-2005, May 2006.

[5] B. Dumas, R. Olivares «Transient Link ControlTechnique Applied to Optical Hybrid Amplifier (EDFA+DFRA) cascades,» Optical Society of America, J. OPT COMMUN. NETW. / Vol. 4, No. 1/November, 2012.

[6] S. Singh and R. S. Kaler,» Novel Optical Flat-Gain Hybrid Amplifier for Dense Wavelength Division Multiplexed System», IEEE Photonics Technology Letters, Vol. 26, No. 2, January 15, 2014.

[7] «Tutorial de Comunicaciones Opticas» [Online]. Available: http://nemesis.tel.uva.es/images/tCO/ contenidos/tema2/tema2_8_2.htm. [Accessed: 03Apr-2016].

[8] G. P. Agrawal., Fiber Optic Communication Systems. John Wiley and Sons, Inc., New York, 2002.

[9] DR. Zimmerman, H. Spiekman. «Amplifiers for the Masses: EDFA, EDWA, and SOA Amplets for Metro and Access Applications.» J. Light wave Technol. 22(1):63-70, 2004.

[10] P. Jain1, K. Vashist, N. Gupta «Comparison Study of Hybrid Optical Amplifier,» IEEE International Journal of Scientific Research Engineering \& Technology (IJSRET), ISSN 2278-0882 Volume 3, Issue 9, December 2014.

[11] C. Kenneth. P. Reichmann, Iannone, X. Zhou, N. Frigo and B. R. Hemenway, «240Km CWDM Transmission Using Cascaded SOA- Raman Hybrid Amplifiers With 70-nm Bandwidth» IEEE photonics technology letters Vol.18, No. 2, 2006.

[12] S. Bhaskar, M.L. Sharma, Ramandeep Kaur,» Performance Comparison of different hybrid amplifiers for different numbers of channels», (IJACSA) International Journal of Advanced Computer Science and Applications, Special Issue on Wireless \& Mobile Networks.

[13] R. Ronak, A. Vashi, H. Desai and H. Amit. «Modeling of Gain Flattening using EDFAEYCDFA in Cascading Mode» International Journal of Emerging Trends \& Technology in Computer Science (IJETTCS), Volume 2, Issue 4, July - August 2013.

[14] I. Kaur and N. Gupta, «Comparative Analysis of Hybrid TDFA-EDFA and Hybrid EDFATDFA Configurations for 96 Channels DWDMSystem for S+C Bands», 2014. IEEE.
[15] T. Sakamoto, S. Aozasa, M. Yamada, and M. Shimizu, «Hybrid Fiber Amplifiers Consisting of Cascaded TDFA and EDFA for WDM Signals» Journal of lightwave technology, Vol. 24, No. 6, June 2006.

[16] M. H. Abu Bakar, A. F. Abas, M. Mokhtar, H. Mohamad, and M. A. Mahdi, «Utilization of stimulated raman scattering as secondary pump on hybrid remotely pump L-band Raman/erbiumdoped fiber amplifier,» Laser Phys., vol. 21, no. 4, pp. 722-728, 2011.

[17] S. D. Emami, P. Hajireza, F. Abd-Rahman, H. A. Abdul-Rashid, H. Ahmad and S. W. Harun,» Wideband hybrid amplifier operating in s-band region» Progress In Electromagnetics Research, PIER 102, 301-313, 2010.

[18] M. M. J. Martini, C. E. S. Castellani, M. J. Pontes, M. R. N. Ribeiro, H. J. Kalinowski, «Multi-pump Optimization for Raman+EDFA Hybrid Amplifiers under Pump Residual Recycling,» International Optoelectronics Conference, p.117-121, Belém, Brazil, 2009.

[19] M. M. J. Martini, C. E. S. Castellani, M. J. Pontes, M. R. N. Ribeiro, H. J. Kalinowski, «Performance Comparison for Raman+EDFA and EDFA+Raman Hybrid Amplifiers Using Recycled Multiple Pump Lasers for WDM Systems,» International Optoelectronics Conference, p. 117 - 121, Belém, Brazil, 2009.

[20] S. Singh and R. S. Kaler, «Review on recent developments in hybrid optical amplifier for dense wavelength division multiplexed system», Optical Engineering 54(10), 100901 (October 2015).

[21] S. Singh and R. S. Kaler, «Flat gain L-band RamanEDFA hybrid optical amplifier for dense wavelength division multiplexed system,» IEEE Photon. Technol. Lett., vol. 25, no. 3, pp. 250-252, Feb. 1, 2013.

[22] S. Singh and R. S. Kaler, «Investigation of hybrid optical amplifiers for dense wavelength division multiplexed system with reduced spacing at higher bit rates,» Fiber Intege. Opt. 31(3), 208-220 (2012).

[23] M. N. Guo et al., «Single-wavelength-pump bidirectional hybrid fiber amplifier for bi-directional local area network application,»Opt. Commun., vol. 284, no. 2, pp. 573-578, 2011.

[24] S. Singh and R. S. Kaler, «Performance evaluation of hybrid optical amplifier for high speed DPSK modulated optical signals,» J. Opt. Eng., vol. 52, no. 9, pp. 096102-1-096102-3, 2013. 